Article

\title{
Replacement of Vanadium by Ferrovanadium in a Ti-Based Body Centred Cubic (BCC) Alloy: Towards a Low-Cost Hydrogen Storage Material
}

\author{
Thomas Bibienne ${ }^{1}$, Catherine Gosselin ${ }^{1}$, Jean-Louis Bobet ${ }^{2}$ and Jacques Huot ${ }^{1, *(1)}$ \\ 1 Institut de Recherche sur l'Hydrogène, Université du Québec à Trois-Rivières, 3351 des Forges, \\ Trois-Rivières, QC G9A-5H7, Canada; thomas.bibienne@gmail.com (T.B.); catherine.gosselin1@uqtr.ca (C.G.) \\ 2 Université de Bordeaux, ICMCB, Métallurgie et Matériaux Fonctionnels, 87 Avenue du Dr Schweitzer, \\ 33600 Pessac, France; jean-louis.bobet@icmcb.cnrs.fr \\ * Correspondence: Jacques.huot@uqtr.ca; Tel.: +1-819-376-5011
}

Received: 28 May 2018; Accepted: 9 July 2018; Published: 15 July 2018

check for updates

Featured Application: Cost reduction of metal hydrides for hydrogen storage.

\begin{abstract}
We report here the effect on hydrogen sorption behavior of replacing vanadium by ferrovanadium (FeV) in Ti-V-Cr Body Centred Cubic (BCC) solid solution alloys. The compositions studied were $\mathrm{Ti}_{1.56} \mathrm{~V}_{0.36} \mathrm{Cr}_{1.08}$ and $\mathrm{Ti}_{1.26} \mathrm{~V}_{0.63} \mathrm{Cr}_{1.11}$. Both of the alloys were synthesized by melting with 4 wt \% of $\mathrm{Zr}_{7} \mathrm{Ni}_{10}$ in order to enhance the first hydrogenation (i.e., activation) kinetics. The ferrovanadium substitution leads to the same microstructure as the vanadium pristine alloys and no significant change in the lattice parameters was found. However, a longer incubation time was observed in the activation process for the FeV substituted alloy. Finally, the replacement of vanadium by ferrovanadium did not have a noticeable impact on the hydrogen capacities, heat of formation, and entropy.
\end{abstract}

Keywords: hydrogen storage; metal hydride; BCC alloys; ferrovanadium

\section{Introduction}

Body Centred Cubic (BCC) Vanadium-based alloys have been studied intensively since Reilly et al. reported that vanadium hydride can store $3.8 \mathrm{wt} \%$ of hydrogen (i.e., dihydride $\mathrm{VH}_{2}$ ) and has a reversible capacity of about $2 \mathrm{wt} \%$ [1-3]. For hydrogen storage applications, one limitation of these alloys is the high price of vanadium. Thus, a low-cost alloy (i.e., with lower vanadium content) could be more attractive for industrial production. Following this idea, the effect of the addition of other transition elements has been studied by many groups [4-12]. In general, upon substitution, the reversible storage capacity decreases, but for most cases, the hydrogen capacity is around $2 \mathrm{wt} \%$, which is acceptable for some applications.

Metal hydrides containing vanadium may be too expensive to be commercially viable. One way to reduce cost is then to replace vanadium by the less expensive ferrovanadium $[9,11,13-19]$. For example, Taizhong et al. found that the alloy $\operatorname{TiCr}_{1.2}(\mathrm{FeV})_{0.6}$ has a total hydrogen capacity of $3.0 \mathrm{wt} \%$ and a reversible capacity of $1.8 \mathrm{wt} \%$ [9]. Kim et al. showed that the as-cast $\mathrm{Ti}_{0.85} \mathrm{Zr}_{0.13}(\mathrm{FeV})_{0.56} \mathrm{Mn}_{1.47} \mathrm{Ni}_{0.05}$ alloys was made of a $\mathrm{C} 14$ Laves phase and the $\mathrm{FeO}$ phase. The origin of the $\mathrm{FeO}$ phase was the replacement of $\mathrm{V}$ by $\mathrm{FeV}$. However, annealing at $1000{ }^{\circ} \mathrm{C}$ for one hour resulted in a single phase with C14 Laves phase with a reversible hydrogen capacity of $1.6 \mathrm{wt} \%$. Santos et al. reported that the alloys $\operatorname{TiMn}_{0.9}(\mathrm{FeV})_{1.1}$ and $\mathrm{TiMn}_{1.1}(\mathrm{FeV})_{0.9}$ have faster activation kinetics than their pure vanadium counterpart [16]. The total hydrogen capacity was lower for the ferrovanadium containing alloys, 
but the reversible capacity was higher due to the modification of the plateau pressures. Recently, Mao et al. synthesized (FeV80) ${ }_{48} \mathrm{Ti}_{26} \mathrm{Cr}_{26}$ by the hydride powder sintering method [11]. They found that the hydrogen capacity was reduced when compared to the melted alloy. However, adding 4 at $\%$ of Ti the sintered sample was shown to have similar hydrogen absorption-desorption capacities than the melted sample. Sakaki et al. studied TiZrMn BCC alloy for metal hydride actuators [19]. They showed that ferrovanadium could be used for cost reduction and that the $\mathrm{Al}$ impurity in ferrovanadium could reduce the hysteresis factor.

Recently, we reported the investigation of $\mathrm{Ti}_{1.56} \mathrm{~V}_{0.36} \mathrm{Cr}_{1.08} \mathrm{Cr}$ and $\mathrm{Ti}_{1.26} \mathrm{~V}_{0.63} \mathrm{Cr}_{1.11}$ alloys, to which $\mathrm{Zr}_{7} \mathrm{Ni}_{10}$ was added to enhance the activation process [20,21]. In order to decrease the cost of these alloys, we investigated the partial replacement of vanadium by ferrovanadium (FeV). For both alloys 50 at\%, vanadium was replaced by ferrovanadium thus obtaining $\mathrm{Ti}_{1.56} \mathrm{~V}_{0.18}(\mathrm{FeV})_{0.18} \mathrm{Cr}_{1.08}$ and $\mathrm{Ti}_{1.26} \mathrm{~V}_{0.315}(\mathrm{FeV})_{0.315} \mathrm{Cr}_{1.11}$ alloys. The effects of partial replacement of $\mathrm{V}$ by $\mathrm{FeV}$ in these Ti-V-Cr alloys on the crystal structure, microstructure, and thermodynamics parameters are presented here.

\section{Materials and Methods}

The raw elements were purchased from Alfa-Aesar and had the following purities: Ti (99.95\%), $\mathrm{V}(99 \%), \mathrm{Cr}(99 \%), \mathrm{Zr}(99.95 \%)$, and $\mathrm{Ni}(99.7 \%)$. The ferrovanadium alloy (FeV) had a composition of $79.88 \mathrm{wt} \% \mathrm{~V} ; 16.26 \mathrm{wt} \% \mathrm{Fe} ; 3.74 \mathrm{wt} \% \mathrm{Al} ; 0.09 \mathrm{wt} \% \mathrm{Si}$; and, $0.03 \mathrm{wt} \% \mathrm{Cr}$.

To facilitate the first hydrogenation (activation) $4 \mathrm{wt} \%$ of $\mathrm{Zr}_{7} \mathrm{Ni}_{10}$ alloy was added to $\mathrm{Ti}_{1.26} \mathrm{~V}_{0.63} \mathrm{Cr}_{1.11}$ and $\mathrm{Ti}_{1.56} \mathrm{~V}_{0.36} \mathrm{Cr}_{1.08}$ alloys using the following synthesis method. In a first step, both $x \mathrm{Ti}-\mathrm{yV}-\mathrm{zCr}$ and $\mathrm{Zr}_{7} \mathrm{Ni}_{10}$ alloys were melted independently. In the second step, both of the alloys were crushed separately in a mortar and pestle, mixed in the right proportion, and remelted together. This process is thereafter called co-melt. More details about this process could be found in our previous paper [21]. Replacement of 50 at\% of vanadium by ferrovanadium was done in both $\mathrm{Ti}_{1.56} \mathrm{~V}_{0.36} \mathrm{Cr}_{1.08}$ and $\mathrm{Ti}_{1.26} \mathrm{~V}_{0.63} \mathrm{Cr}_{1.11}$ alloys. In order to simplify, the name ' $50 \% \mathrm{FeV}^{\prime}$ refer to the composition were 50 at $\%$ of vanadium was replaced by ferrovanadium and ' $100 \% \mathrm{FeV}^{\prime}$ to the composition where $100 \mathrm{at} \%$ of vanadium was replaced.

In casting, each sample was turned over and melted three times to ensure homogeneity. The X-ray diffraction patterns were acquired on a Bruker D8 Focus apparatus using $\mathrm{Cu} k \alpha$ radiation. The crystallographic parameters (lattice parameters, crystallite size, and strain) were evaluated by Rietveld's refinement of the X-ray diffraction patterns using Topas software [22]. The refined crystal parameters are quoted with three standard deviations.

The microstructure was investigated with a Tescan Vega3 SEM. An Electron Probe Micro Analysis (EPMA, CAMECA SX 100), coupled with Wavelength Dispersive (WDS), was used for mapping the elements.

Pressure-Composition-Isotherms were measured using a home-made Sievert-type apparatus. Each sample was crushed using a mortar and pestle under argon atmosphere to prevent oxidation and then exposed to hydrogen without prior treatment. Activations were performed at room temperature under $2 \mathrm{MPa}$ of $\mathrm{H}_{2}$. Desorptions were performed at $400{ }^{\circ} \mathrm{C}$ under dynamic vacuum for $4 \mathrm{~h}$.

\section{Results}

\section{1. $\mathrm{Ti}_{1.56} \mathrm{~V}_{0.18}(\mathrm{FeV})_{0.18} \mathrm{Cr}_{1.08}+4 w t \% \mathrm{Zr}_{7} \mathrm{Ni}_{10}$}

\subsubsection{Microstructure}

Figure 1 shows the microstructure and elements distribution of the $\operatorname{Ti}_{1.56} \mathrm{~V}_{0.18}(\mathrm{FeV})_{0.18} \mathrm{Cr}_{1.08}+4 \%$ $\mathrm{Zr}_{7} \mathrm{Ni}_{10}$ co-melt alloy. Two distinct phases are present: a main dark phase and a bright secondary phase. The secondary phase is evenly distributed and the size of each 'island' of secondary phase is of the order of a few microns. The element mapping indicates that the secondary phase is rich in zirconium and nickel elements. 


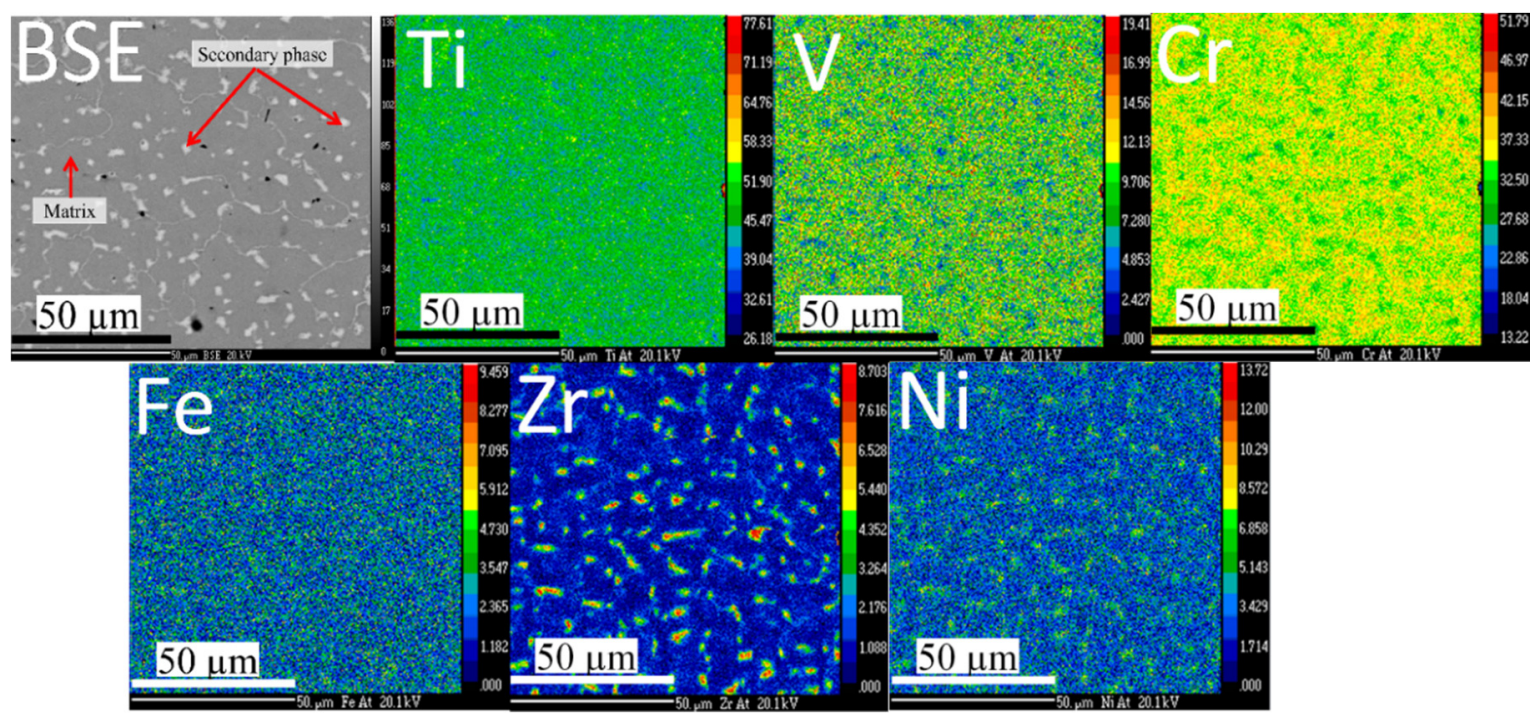

Figure 1. Backscattered micrograph and elements mappings of the as-cast co-melt $\mathrm{Ti}_{1.56} \mathrm{~V}_{0.18}(\mathrm{FeV})_{0.18} \mathrm{Cr}_{1.08}$ $+4 \% \mathrm{Zr}_{7} \mathrm{Ni}_{10}$ alloy.

Figure 2 shows a quantitative chemical analysis using EDX. The two lines (A and B on Figure 2) analysis clearly indicate that the amount of titanium, vanadium, and chromium slightly decrease in the secondary phase when compared to the matrix. Iron and nickel are almost exclusively found in the secondary phase. As far as zirconium is concerned, a small proportion is present in the matrix, but its abundance is much higher in the secondary phase. The quantitative analysis is reported in Table 1. One can notice in Table 1 that a relative variation of element abundance between the matrix and the secondary phase can be seen for iron, zirconium, and nickel, while the smallest variations are noticed for titanium and chromium. The matrix phase has a chemical composition that is very close to the nominal one except that zirconium and nickel are is a very low concentration. These two elements are almost exclusively found in the secondary phase, in which vanadium content is much reduced when compared to the matrix, but titanium and chromium concentrations are very similar to the ones that are found in the matrix.

Table 1. Nominal and measured atomic percentage of the as-cast co-melt $52 \mathrm{Ti}-6 \mathrm{~V}-6 \mathrm{FeV}-36 \mathrm{Cr}+4 \% \mathrm{Zr}_{7} \mathrm{Ni}_{10}$. Uncertainties on the last significant digits are quoted in parentheses.

\begin{tabular}{cccc}
\hline Element & Bulk Nominal Value & Matrix & Secondary Phase \\
\hline $\mathrm{Ti}$ & 50.6 & $50.2(4)$ & $47.0(3)$ \\
$\mathrm{Fe}$ & 1.0 & $0.83(1)$ & $1.6(1)$ \\
$\mathrm{V}$ & 10.7 & $11.3(1)$ & $7.4(2)$ \\
$\mathrm{Cr}$ & 35.0 & $35.6(5)$ & $34(2)$ \\
$\mathrm{Zr}$ & 1.1 & $0.7(4)$ & $5.7(1)$ \\
$\mathrm{Ni}$ & 1.6 & $1.3(1)$ & $4.5(3)$ \\
\hline
\end{tabular}




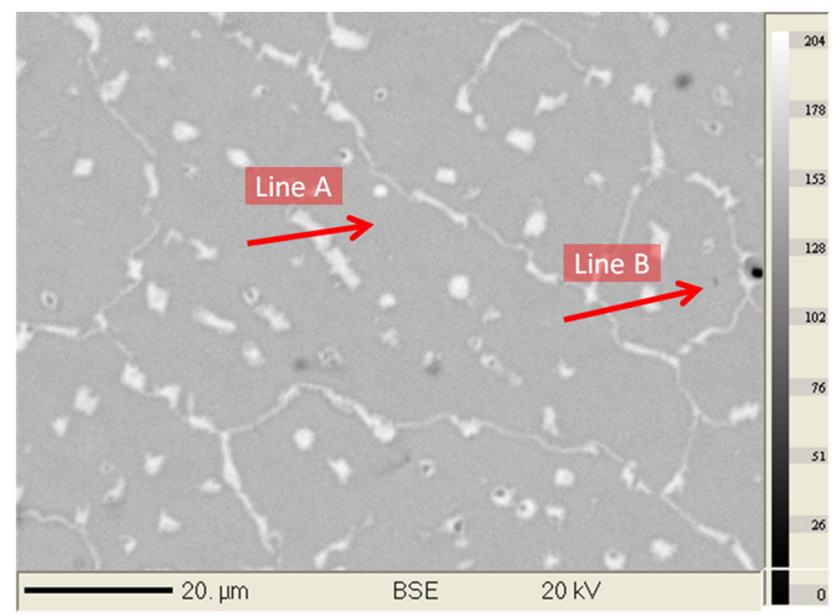

Line A

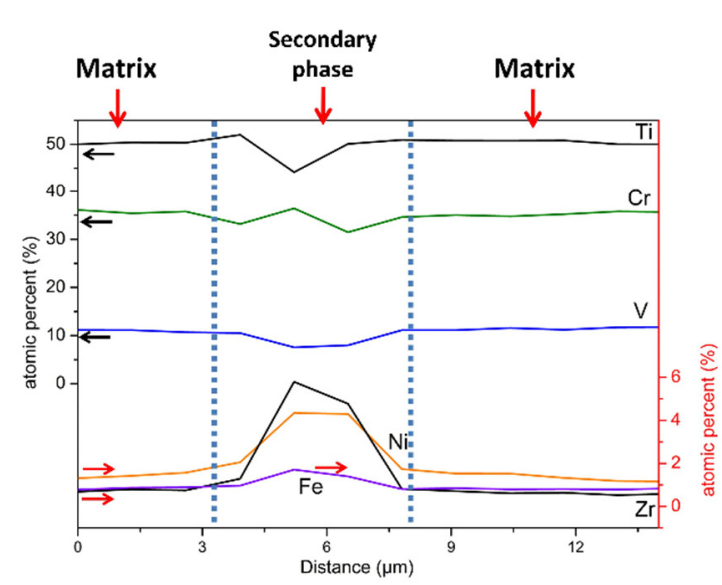

$\underline{\text { Line B }}$

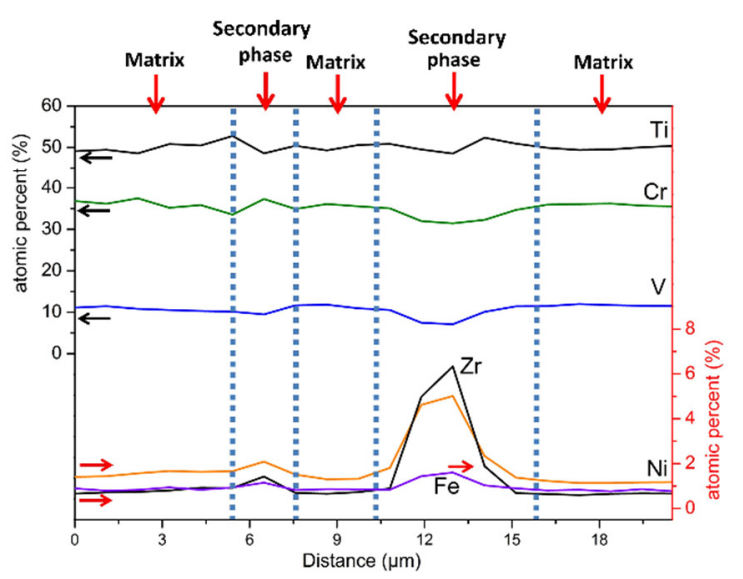

Figure 2. Linear chemical analysis of the as-cast co-melt $\mathrm{Ti}_{1.56} \mathrm{~V}_{0.18}(\mathrm{FeV})_{0.18} \mathrm{Cr}_{1.08}+4 \% \mathrm{Zr}_{7} \mathrm{Ni}_{10}$ alloy; lines positions are indicated on the backscattered electrons (BSE) SEM micrograph.

\subsubsection{Crystal Structure}

The alloy's crystal structure was investigated by X-ray powder diffraction. Diffraction patterns of co-melt $\mathrm{Ti}_{1.56} \mathrm{~V}_{0.18}(\mathrm{FeV})_{0.18} \mathrm{Cr}_{1.08}+4 \% \mathrm{Zr}_{7} \mathrm{Ni}_{10}$ taken in as cast, hydrogenated and dehydrogenated states are shown in Figure 3. The as-cast pattern only shows the BCC structure and there is no evidence of a secondary phase. As seen in Figures 1 and 2, the proportion of secondary phase is quite small, thus making it harder to identify by X-ray diffraction. Also, it is clear from the atomic compositions of both phases presented in Table 1 that both BCC alloys have an almost similar bulk composition. Therefore, even if the crystal structure of the secondary phase remains unknown, there is a strong probability that it exhibits the same crystal structure as the matrix phase. According to our calculations that are based on the diameter of every element provided by the Shannon's Table, the average metallic radii in both the matrix and the secondary phase were estimated to be, respectively, $0.1392 \mathrm{~nm}$ and $0.1401 \mathrm{~nm}$ [23]. This means that, if the matrix and secondary phase have both a BCC structure and if one of them has a much lower abundance than the other, then it may be effectively impossible to distinguish them using the powder X-ray diffraction technique. Assuming the same crystal structure and the average metallic radius, we calculated a shift in the Bragg's peaks of only $0.01^{\circ}$ at $42^{\circ}$ and $0.1^{\circ}$ at $104^{\circ}$. As the secondary phase abundance is much lower than the main phase, its peak will be effectively 'buried' under the main phase peaks. 


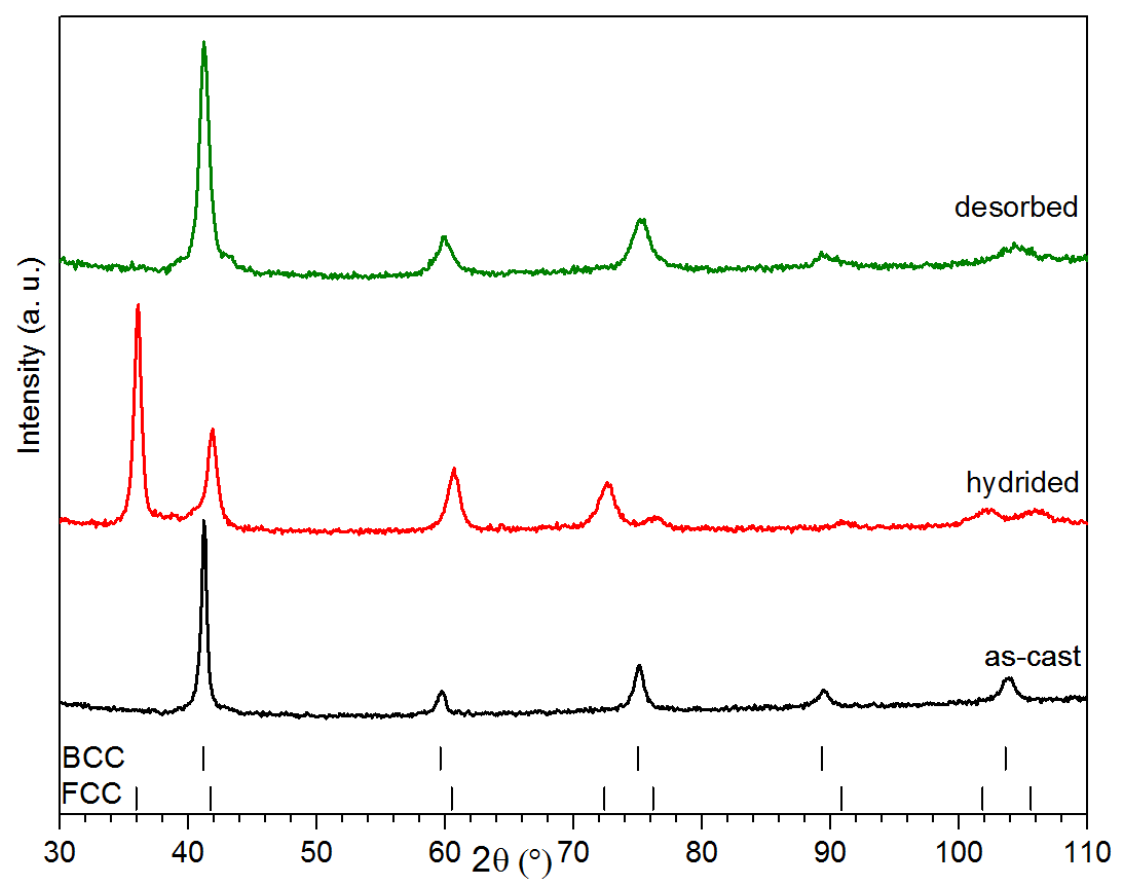

Figure 3. XRD pattern of the co-melt $\mathrm{Ti}_{1.56} \mathrm{~V}_{0.18}(\mathrm{FeV})_{0.18} \mathrm{Cr}_{1.08}+4 \% \mathrm{Zr}_{7} \mathrm{Ni}_{10}$ alloy in as cast, fully hydride, and desorbed state.

Rietveld refinements were performed on the three patterns and results are shown in Table 2. The values that are reported in this table are essentially identical to the one reported in our previous investigation on the alloy $\mathrm{Ti}_{1.56} \mathrm{~V}_{0.36} \mathrm{Cr}_{1.08}+4 \% \mathrm{Zr}_{7} \mathrm{Ni}_{10}$ [21]. The main discrepancies are the slightly less important reduction of crystallite size upon dehydrogenation and a larger increase of micro-strain after hydrogenation. Nevertheless, it seems that the partial replacement of vanadium has no important effect on the crystal structure of the BCC alloy.

Table 2. Crystal parameters of the co-melt $\mathrm{Ti}_{1.56} \mathrm{~V}_{0.18}(\mathrm{FeV})_{0.18} \mathrm{Cr}_{1.08}+4 \% \mathrm{Zr}_{7} \mathrm{Ni}_{10}$.

\begin{tabular}{ccccc}
\hline Sample & Crystal Structure & Lattice Parameter $(\mathbf{n m})$ & Crystallite Size (nm) & Micro-Strain (\%) \\
\hline As-cast & BCC & $0.3100(1)$ & $14(1)$ & $0.4(1)$ \\
Hydrided & FCC & $0.4326(3)$ & $13(2)$ & $1.4(1)$ \\
Desorbed & BCC & $0.3089(3)$ & $8(1)$ & $1.2(2)$ \\
\hline
\end{tabular}

Rietveld refinements of the patterns that are displayed in Figure 3 also enable us to estimate the stoichiometry of the hydride sample. From the lattice parameters, the formula unit volume was calculated to be $14.89 \AA^{3}$ for the BCC structure of the as-cast sample. Regarding its Face Centred Cubic (FCC) hydride counterpart, a volume of $20.24 \AA^{3}$ was estimated, corresponding to an expansion of $5.35 \AA^{3}$ per formula unit. Using the Westlake's criteria claiming a volume change comprised between 2 and $3 \AA^{3}$ for each hydrogen atom absorbed, the cell structure expansion is consistent with a dihydride FCC phase $\left(\mathrm{Ti}_{1.56} \mathrm{~V}_{0.36} \mathrm{Cr}_{1.08}\right) \mathrm{H}_{2}$.

\subsubsection{Hydrogen Storage Properties}

The kinetics of the first hydrogenation (activation) under 2MPa of hydrogen at room temperature of the $\mathrm{Ti}_{1.56} \mathrm{~V}_{0.18}(\mathrm{FeV})_{0.18} \mathrm{Cr}_{1.08}+4 \% \mathrm{Zr}_{7} \mathrm{Ni}_{10}$ and $\mathrm{Ti}_{1.56} \mathrm{~V}_{0.36} \mathrm{Cr}_{1.08}+4 \% \mathrm{Zr}_{7} \mathrm{Ni}_{10}$ alloys are presented in Figure 4 . The activation is similar for both of the alloys, the only difference being a slightly longer incubation time for the ferrovanadium-containing sample. After the incubation time, the absorption proceeds quite rapidly and full capacity is reached in less than $300 \mathrm{~s}$ for both pure vanadium and 
vanadium substituted alloys. The maximum capacity is close to $3.2 \mathrm{wt} \%$ of hydrogen, which is slightly higher than other Ti-V based materials that was reported in the literature [24-27].

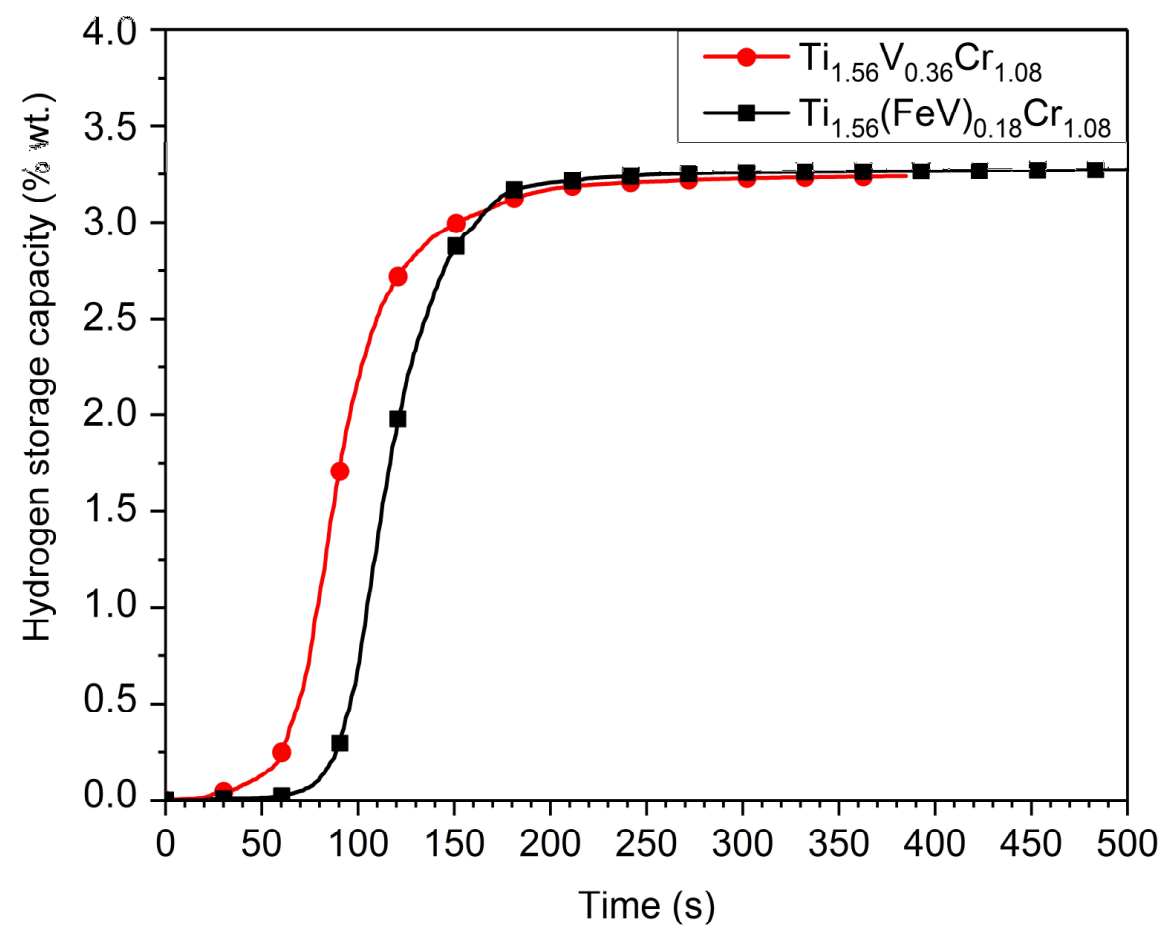

Figure 4. Activation kinetics of the co-melt $\mathrm{Ti}_{1.56} \mathrm{~V}_{0.18}(\mathrm{FeV})_{0.18} \mathrm{Cr}_{1.08}+4 \% \mathrm{Zr}_{7} \mathrm{Ni}_{10}$ and $\mathrm{Ti}_{1.56} \mathrm{~V}_{0.36} \mathrm{Cr}_{1.08}$ $+4 \% \mathrm{Zr}_{7} \mathrm{Ni}_{10}$ under 20 bars of $\mathrm{H}_{2}$ at $25^{\circ} \mathrm{C}$.

After activation, the samples were desorbed and the pressure-composition isotherm was registered. However, we found out that there was an important reduction of capacity that makes the measurement practically impossible. For this reason, after activation at room temperature, the temperature was increased while keeping the sample under high hydrogen pressure in order to prevent it to desorb. Thereafter, the desorption curve was registered. This procedure was repeated for each isotherm, meaning that every isotherm was measured using a freshly hydrided sample. Figure 5 gathers the Pressure Composition desorption isotherms (PCT) that were recorded at 150, 180,200 , and $230^{\circ} \mathrm{C}$. For each temperature, a few measurements were performed with similar results. As the temperature increases, so does the equilibrium pressure. It should be mentioned that the plateau recorded are for the transition from the dihydride to the monohydride. The monohydride plateau is too stable to be recorded with our apparatus. The fact that the plateaus are sloped is probably due to the solid solution nature of the as-cast material. As there is an important reduction of capacity after the first cycle, this may explain why the capacities of various isotherms changed. Further work on cycling properties of this material is needed. This is also the reason why we considered the middle of each plateau as the plateau pressure and not the hydrogen pressure at a given hydrogen concentration. The fact that the capacity increases with temperature is puzzling. One reason may be the lowering of the first plateau that makes the transition from the first to second plateau even more sloping, thus making the measurement of total capacity of the second plateau more difficult. From these pressures, a Van't Hoff plot was obtained and is reported in Figure 5. The formation enthalpy of the hydride has been determined to be $-59 \pm 3 \mathrm{~kJ} \cdot\left(\mathrm{mol} \cdot \mathrm{H}_{2}\right)^{-1}$ and its associated entropy $-166 \pm 8 \mathrm{~J} \cdot\left(\mathrm{mol} \cdot \mathrm{H}_{2}\right)^{-1} \cdot \mathrm{K}^{-1}$. The errors have been calculated using the linear fit of the Van't Hoff plot. As a comparison, the formation enthalpy of the $\mathrm{Ti}_{1.56} \mathrm{~V}_{0.36} \mathrm{Cr}_{1.08}+4 \% \mathrm{Zr}_{7} \mathrm{Ni}_{10}$ hydride has been determined to be $-61 \mathrm{~kJ} \cdot\left(\mathrm{mol} \cdot \mathrm{H}_{2}\right)^{-1}$ and its associated entropy $-169 \mathrm{~J} \cdot\left(\mathrm{mol} \cdot \mathrm{H}_{2}\right)^{-1} \cdot \mathrm{K}^{-1}$ [21]. 


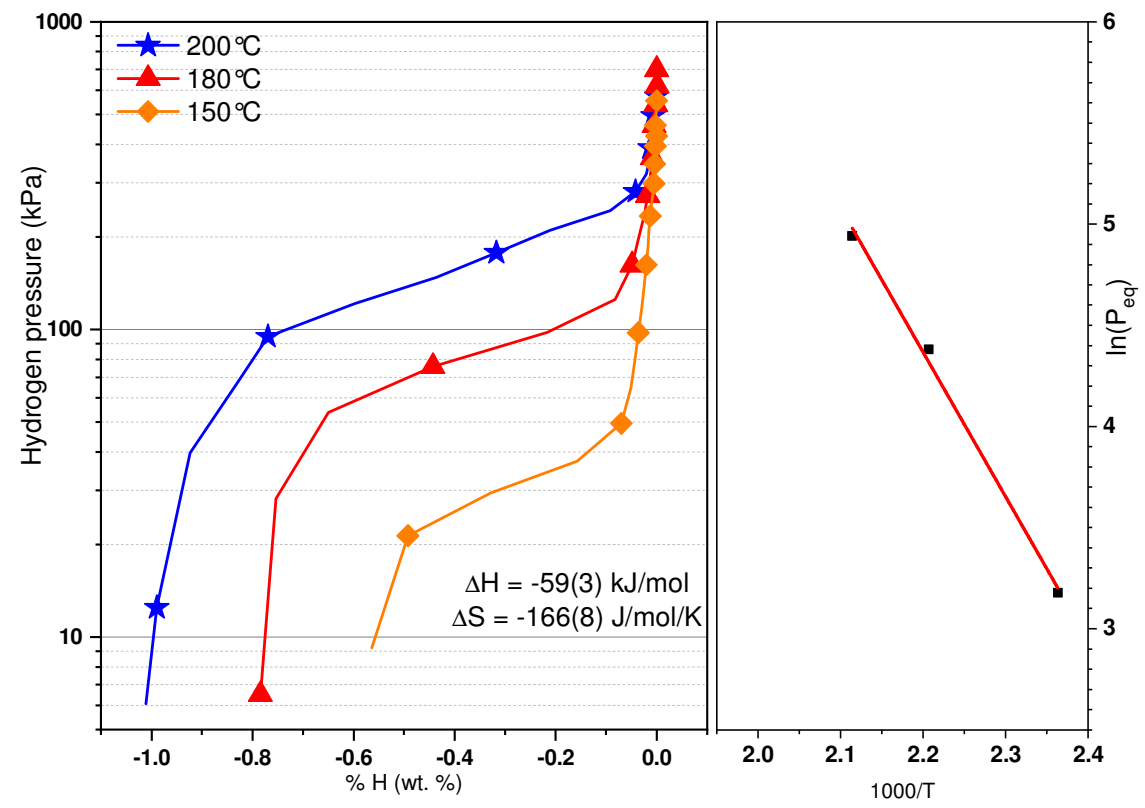

Figure 5. Desorption the Pressure Composition desorption isotherms (PCTs) at 150, 180, and $200{ }^{\circ} \mathrm{C}$ and $\ln (\mathrm{Peq})$ vs $(1000 / \mathrm{T})$ of the co-melt $\mathrm{Ti}_{1.56} \mathrm{~V}_{0.18}(\mathrm{FeV})_{0.18} \mathrm{Cr}_{1.08}+4 \% \mathrm{Zr}_{7} \mathrm{Ni}_{10}$.

The high value of the entropy term when compared to the usual one found in metal hydrides (103 to $115 \mathrm{~J} \cdot\left(\mathrm{mol} \cdot \mathrm{H}_{2}\right)^{-1} \cdot \mathrm{K}^{-1}$ ) should be addressed. We recently made a series of experiments on the alloys $\mathrm{Ti}_{1-\mathrm{x}} \mathrm{V}_{\mathrm{x}} \mathrm{Cr}_{37}$ and found some evidences of an entropy-enthalpy compensation in these alloys. As this is a controversial subject and may be due to some experimental bias, the investigation is still in progress. But, the preliminary results seems to indicate that $\Delta \mathrm{H}$ is directly proportional to $\Delta \mathrm{S}$ in these alloys [28].

\section{2. $\mathrm{Ti}_{1.26} \mathrm{~V}_{0.315}(\mathrm{FeV})_{0.315} \mathrm{Cr}_{1.11}+4 w t \% \mathrm{Zr}_{7} \mathrm{Ni}_{10}$}

\subsubsection{Microstructure}

The other composition studied was $\mathrm{Ti}_{1.26} \mathrm{~V}_{0.315}(\mathrm{FeV})_{0.315} \mathrm{Cr}_{1.11}$ doped with 4 wt $\%$ of $\mathrm{Zr}_{7} \mathrm{Ni}_{10}$. This composition was selected because we have already studied the composition $\mathrm{Ti}_{1.26} \mathrm{~V}_{0.63} \mathrm{Cr}_{1.11}$ [20]. Figure 6 shows the microstructure and elements mapping of as cast co-melt $\mathrm{Ti}_{1.26} \mathrm{~V}_{0.315}(\mathrm{FeV})_{0.315} \mathrm{Cr}_{1.11}$ $+4 \mathrm{wt} \% \mathrm{Zr}_{7} \mathrm{Ni}_{10}$. It is clear that, as for the previous composition, the alloy is made of a main and a secondary phase where the secondary phase is depleted in chromium and vanadium but is rich in zirconium and nickel.

A quantitative analysis of element abundance is shown in Figure 7 and the values are reported in Table 3. The situation is similar to what has been observed for the sample $\mathrm{Ti}_{1.56} \mathrm{~V}_{0.18}(\mathrm{FeV})_{0.18} \mathrm{Cr}_{1.08}+$ $4 \% \mathrm{Zr}_{7} \mathrm{Ni}_{10}$. It shows that $\mathrm{Fe}, \mathrm{Zr}$, and $\mathrm{Ni}$ elements are principally found in the secondary phase and that chromium and vanadium concentrations are depleted when compared to the main phase. The only difference with the previous alloy consists of a higher titanium abundance in the secondary phase than in the matrix. 


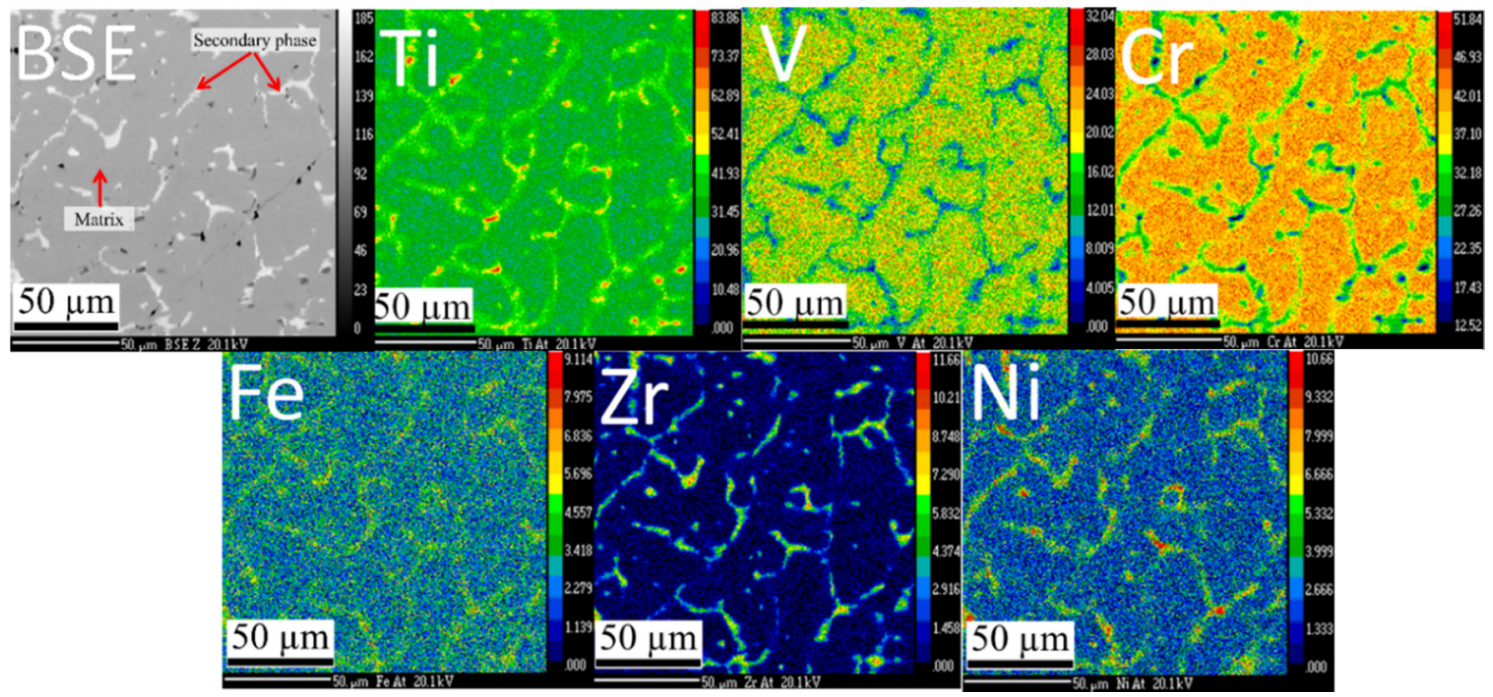

Figure 6. BSE SEM micrograph and Electron Probe Micro Analysis (EPMA) mapping of the as-cast $\mathrm{Ti}_{1.26} \mathrm{~V}_{0.315}(\mathrm{FeV})_{0.315} \mathrm{Cr}_{1.11}+4 \% \mathrm{Zr}_{7} \mathrm{Ni}_{10}$.

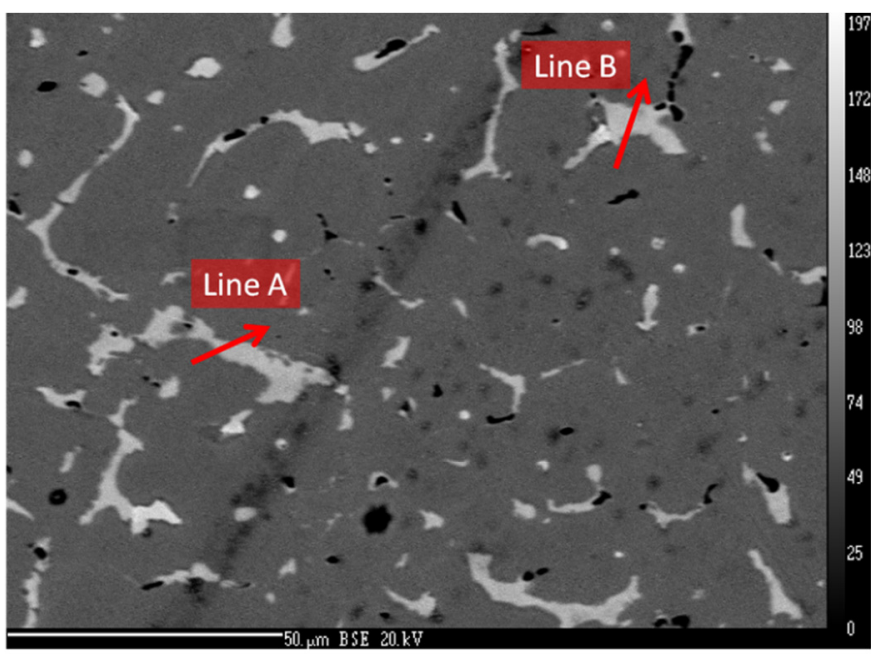

\section{Line A}

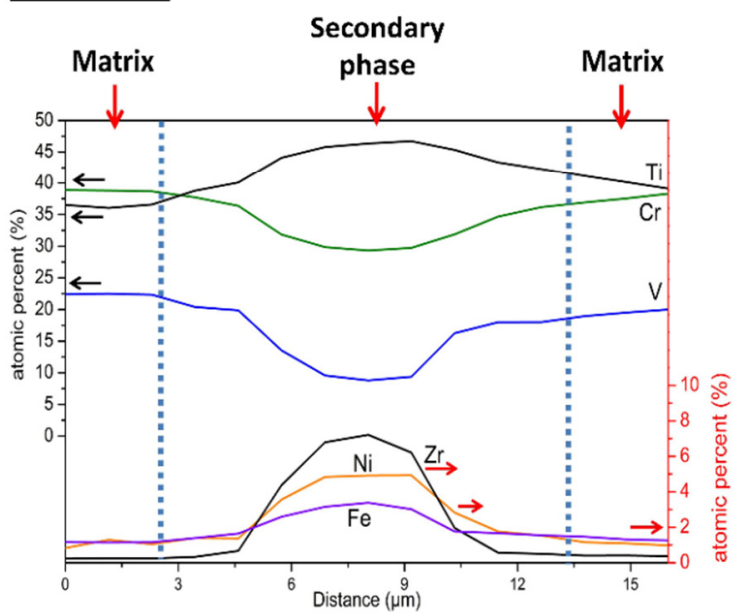

Line B

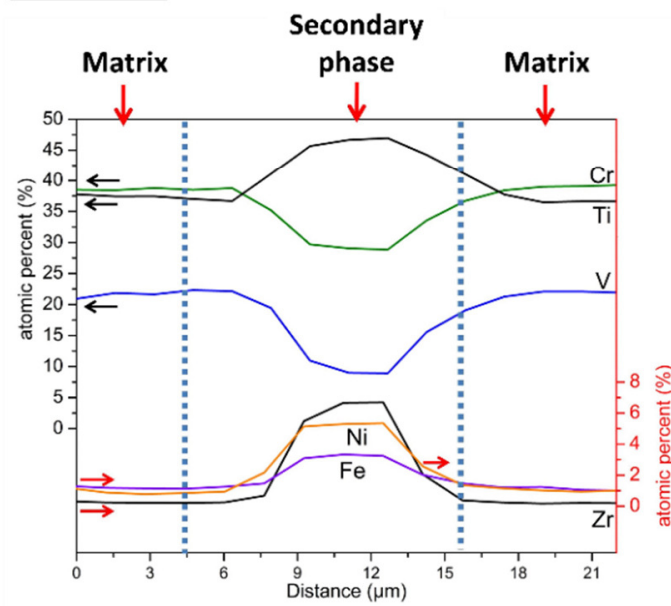

Figure 7. Linear chemical analysis of the as-cast co-melt $\mathrm{Ti}_{1.26} \mathrm{~V}_{0.315}(\mathrm{FeV})_{0.315} \mathrm{Cr}_{1.11}+4 \% \mathrm{Zr}_{7} \mathrm{Ni}_{10}$ alloy; lines positions are indicated on the BSE SEM micrograph. 
Table 3. Nominal and measured atomic percentage of the as-cast co-melt $\mathrm{Ti}_{1.26} \mathrm{~V}_{0.315}(\mathrm{FeV})_{0.315} \mathrm{Cr}_{1.11}$ $+4 \% \mathrm{Zr}_{7} \mathrm{Ni}_{10}$ alloy.

\begin{tabular}{cccc}
\hline Element & Bulk Nominal Value & Matrix & Secondary Phase \\
\hline $\mathrm{Ti}$ & 40.9 & $38(2)$ & $47(2)$ \\
$\mathrm{Fe}$ & 1.7 & $1.2(1)$ & $3.1(1)$ \\
$\mathrm{V}$ & 18.7 & $21(1)$ & $9.5(2)$ \\
$\mathrm{Cr}$ & 36.0 & $38.5(5)$ & $29.5(4)$ \\
$\mathrm{Zr}$ & 1.1 & $0.3(1)$ & $6.3(1)$ \\
$\mathrm{Ni}$ & 1.6 & $1.0(1)$ & $5.1(2)$ \\
\hline
\end{tabular}

\subsubsection{Crystal Structure}

Figure 8 presents the $\mathrm{X}$-ray diffraction patterns of the as-cast, hydrided, and desorbed $\mathrm{Ti}_{1.26} \mathrm{~V}_{0.315}(\mathrm{FeV})_{0.315} \mathrm{Cr}_{1.11}+4 \% \mathrm{Zr}_{7} \mathrm{Ni}_{10}$ alloy. Table 4 presents the crystal structure parameters, as determined by Rietveld refinements.

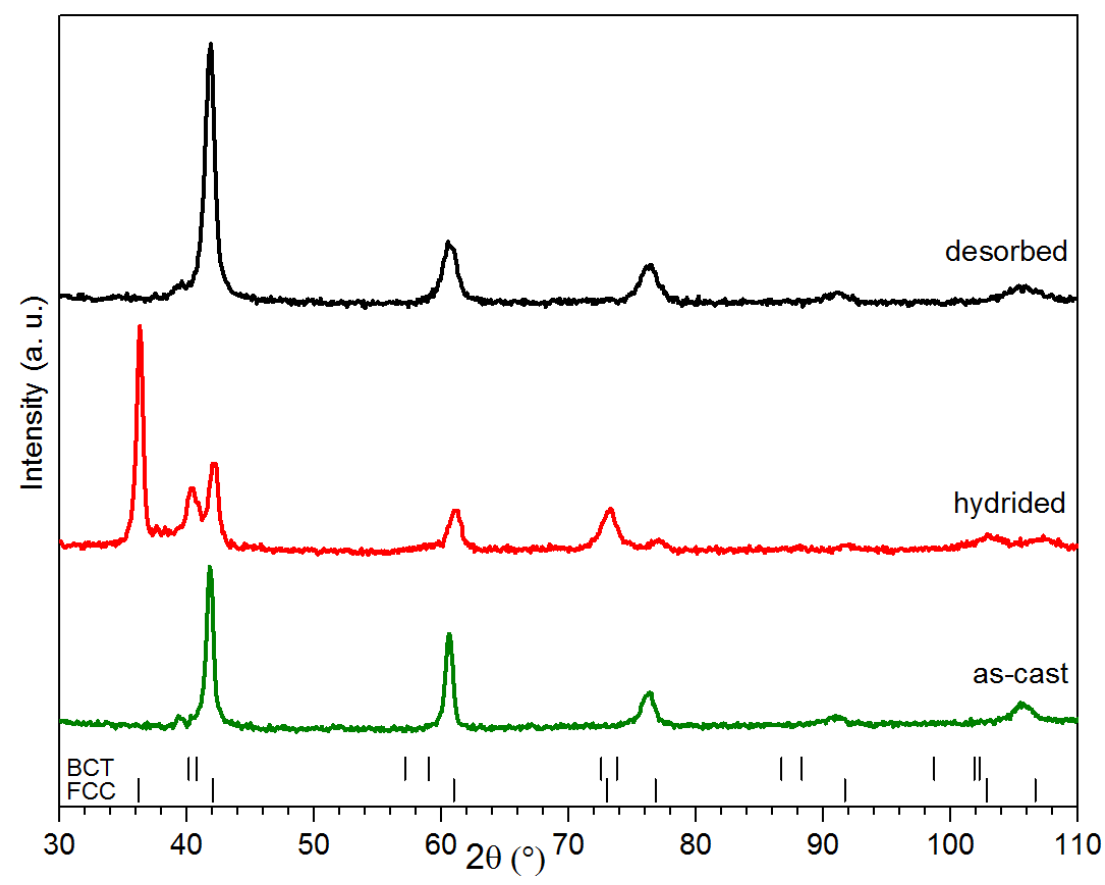

Figure 8. $\mathrm{XRD}$ patterns of $\mathrm{Ti}_{1.26} \mathrm{~V}_{0.315}(\mathrm{FeV})_{0.315} \mathrm{Cr}_{1.11}+4 \% \mathrm{Zr}_{7} \mathrm{Ni}_{10}$ alloy.

Table 4. Crystal parameters of the co-melt $\mathrm{Ti}_{1.26} \mathrm{~V}_{0.315}(\mathrm{FeV})_{0.315} \mathrm{Cr}_{1.11}+4 \% \mathrm{Zr}_{7} \mathrm{Ni}_{10}$. Uncertainties on last significant digit are indicated in parentheses.

\begin{tabular}{ccccc}
\hline Sample & Crystal Structure & Lattice Parameter $(\mathbf{n m})$ & Crystallite Size $(\mathbf{n m})$ & Micro-Strain $(\mathbf{\%})$ \\
\hline As-cast & BCC & $0.3062(2)$ & $13(1)$ & $0.6(1)$ \\
Hydrided & FCC & $0.4296(3)$ & $16(2)$ & $1.1(1)$ \\
Desorbed & BCC & $0.3059(4)$ & $10(1)$ & $1.2(2)$ \\
\hline
\end{tabular}

The as-cast alloy crystallizes with a BCC structure, as reported for its 100 at\% vanadium homologous alloy and has a slightly smaller lattice parameter $(0.3062 \mathrm{~nm}$ as compared to $0.3074 \mathrm{~nm}$ for the $\mathrm{Ti}_{1.26} \mathrm{~V}_{0.63} \mathrm{Cr}_{1.11}$ alloy) [20]. From the value of lattice parameter of Table 4, the volume of the formula unit was found to be $14.34 \AA^{3}$. The diffraction pattern of the hydride sample clearly shows two phases. One of these phases is the dihydride FCC phase. The other phase is more difficult to determine, and two possibilities were investigated: (1) a BCC phase with hydrogen in solid solution 
and (2) a monohydride BCT (body centered tetragonal) phase. The Rietveld refinement using both structures gave similar Goodness-of-fit and R-values. It should be noted that the formula unit volume was exactly the same $\left(15.76 \AA^{3}\right)$ for both BCT and BCC phases, thus corresponding to an expansion of $1.42 \AA^{3}$. It is very close to one fourth of the expansion of the FCC phase. Therefore, even if we could not precisely determine the crystal structure of this second phase, we are confident that it contains about one hydrogen atom for two formula units.

\subsubsection{Hydrogen Storage Properties}

The kinetics of the hydrogen activation of the $\mathrm{Ti}_{1.26} \mathrm{~V}_{0.315}(\mathrm{FeV})_{0.315} \mathrm{Cr}_{1.11}+4 \% \mathrm{Zr}_{7} \mathrm{Ni}_{10}$ and co-melt $\mathrm{Ti}_{1.26} \mathrm{~V}_{0.63} \mathrm{Cr}_{1.11}+4 \% \mathrm{Zr}_{7} \mathrm{Ni}_{10}$ are presented in Figure 9. The main difference is clearly that the alloy containing ferrovanadium presents a long incubation time, while hydrogen absorption starts immediately for the alloy with pure vanadium. For both alloys, the full capacity is reached in about $200 \mathrm{~s}$ after the reaction started. The maximum capacity of ferrovanadium alloy ( $3.2 \mathrm{wt} \%$ of hydrogen) is slightly smaller than its pure vanadium counterpart (3.4 wt \%).

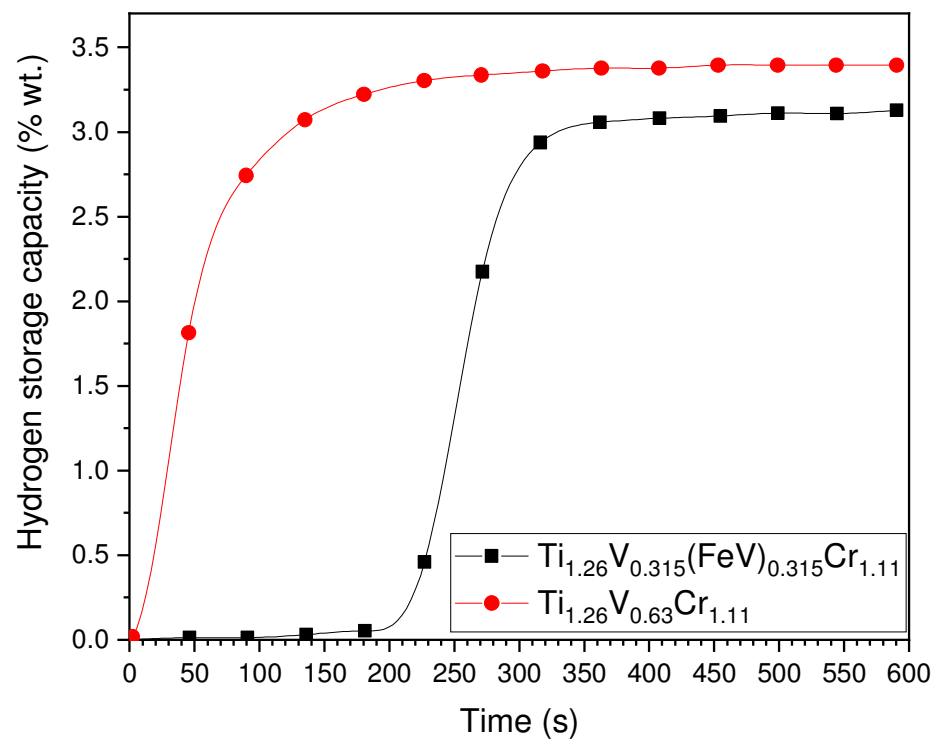

Figure 9. Activation under 20 bars of $\mathrm{H}_{2}$ at $25{ }^{\circ} \mathrm{C}$ of the co-melt $\mathrm{Ti}_{1.26} \mathrm{~V}_{0.315}(\mathrm{FeV})_{0.315} \mathrm{Cr}_{1.11}+4 \%$ $\mathrm{Zr}_{7} \mathrm{Ni}_{10}$ and co-melt $\mathrm{Ti}_{1.26} \mathrm{~V}_{0.63} \mathrm{Cr}_{1.11}+4 \% \mathrm{Zr}_{7} \mathrm{Ni}_{10}$.

From Figures 4 and 9 we see that replacement of vanadium by ferrovanadium made the first hydrogenation starts only after an incubation time. Once the reaction starts, the intrinsic kientics is almost the same as for the alloy without ferrovanadium. The reason of appearance of this incubation time is still not clear. One possible reason may be the nature of the surface of the particles. Alloys that are containing iron may have a thicker oxide on surface, thus making the incubation time longer. But, this hypothesis has to be confirmed by further tests.

Figure 10 exhibits the Pressure Composition desorption isotherms (PCT) of $\mathrm{Ti}_{1.26} \mathrm{~V}_{0.63} \mathrm{Cr}_{1.11}+$ $4 \% \mathrm{Zr}_{7} \mathrm{Ni}_{10}$ recorded at 80,100 and $130{ }^{\circ} \mathrm{C}$. Once again, as the temperature increases, so does the equilibrium pressure. A Van't Hoff plot has been made using the pressure value at the middle of the plateau. The formation enthalpy of the hydride has been determined to be $-38 \mathrm{~kJ} \cdot\left(\mathrm{mol} \cdot \mathrm{H}_{2}\right)^{-1}$ and its associated entropy $-138 \mathrm{~J} \cdot\left(\mathrm{mol} \cdot \mathrm{H}_{2}\right)^{-1} \cdot \mathrm{K}^{-1}$. These values are very close to the ones found for $\mathrm{Ti}_{1.26} \mathrm{~V}_{0.63} \mathrm{Cr}_{1.11}+4 \% \mathrm{Zr}_{7} \mathrm{Ni}_{10}$ hydride, which were determined to be $-38 \mathrm{~kJ} \cdot\left(\mathrm{mol} \cdot \mathrm{H}_{2}\right)^{-1}$ and its associated entropy $-125 \mathrm{~J} \cdot\left(\mathrm{mol} \cdot \mathrm{H}_{2}\right)^{-1} \cdot \mathrm{K}^{-1}[13]$. 


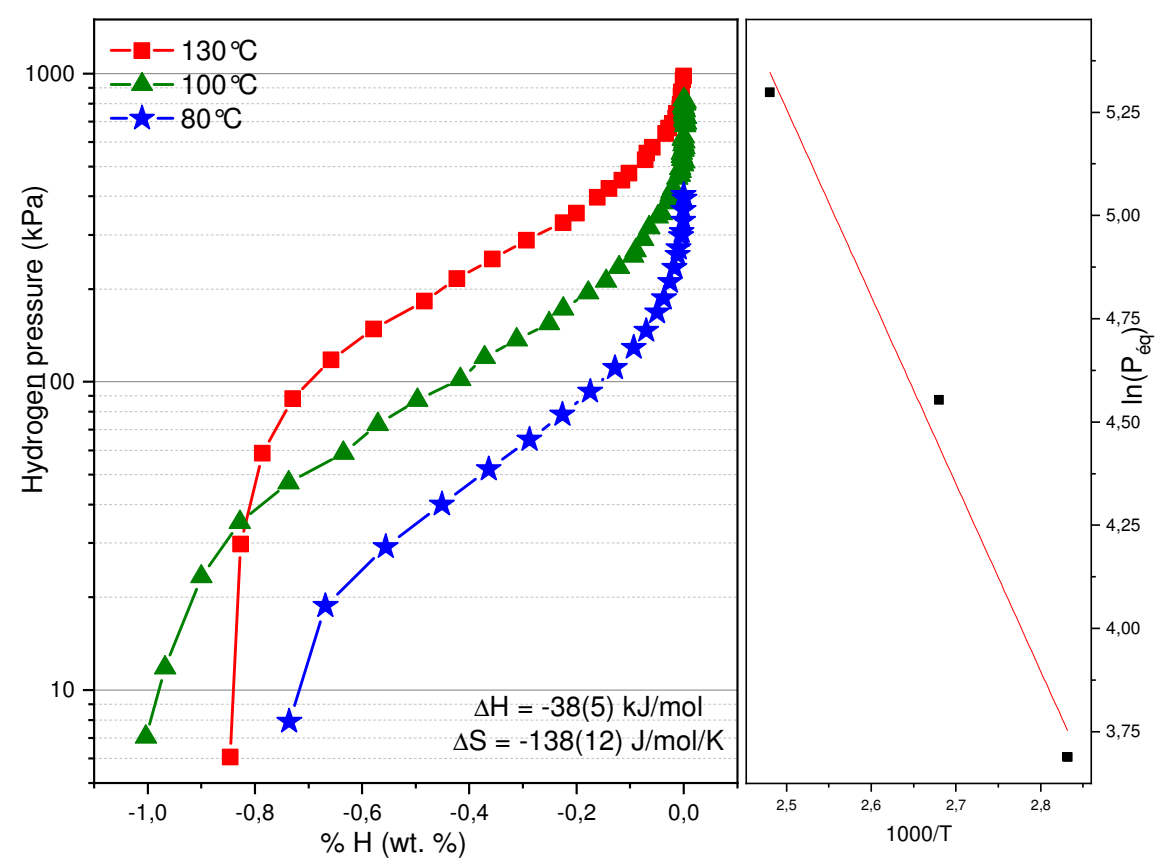

Figure 10. Desorption PCTs at 80, 100, and $130{ }^{\circ} \mathrm{C}$ and $\ln$ (Peq) vs. (1000/T) of the co-melt $\mathrm{Ti}_{1.26} \mathrm{~V}_{0.315}(\mathrm{FeV})_{0.315} \mathrm{Cr}_{1.11}+4 \% \mathrm{Zr}_{7} \mathrm{Ni}_{10}$.

\section{Conclusions}

The microstructure, crystal structure, and hydrogen sorption properties of $\mathrm{Ti}_{1.56} \mathrm{~V}_{0.18}(\mathrm{FeV})_{0.18} \mathrm{Cr}_{1.08}$ +4 wt $\% \mathrm{Zr}_{7} \mathrm{Ni}_{10}$ and $\mathrm{Ti}_{1.26} \mathrm{~V}_{0.315}(\mathrm{FeV})_{0.315} \mathrm{Cr}_{1.11}+4 \mathrm{wt} \% \mathrm{Zr}_{7} \mathrm{Ni}_{10}$ were investigated. Both of the alloys consisted of two phases. The main phase had a BCC structure and a composition that was close to the nominal one, but with minor inclusions of iron, zirconium, and nickel. For the $\mathrm{Ti}_{1.56} \mathrm{~V}_{0.18}(\mathrm{FeV})_{0.18} \mathrm{Cr}_{1.08}$ $+4 \mathrm{wt} \% \mathrm{Zr}_{7} \mathrm{Ni}_{10}$, the secondary phase is depleted in vanadium. In the case of $\mathrm{Ti}_{1.26} \mathrm{~V}_{0.315}\left(\mathrm{FeV}_{0.315} \mathrm{Cr}_{1.11}\right.$ $+4 \mathrm{wt} \% \mathrm{Zr}_{7} \mathrm{Ni}_{10}$, the secondary phase is depleted in vanadium and chromium, while titanium is more abundant than in the main phase. For both alloys, the secondary phase has much higher proportion of iron, zirconium, and nickel than in the main phase.

For both compositions, we evidenced that a replacement of 50 at $\%$ of vanadium by ferrovanadium did not significantly change the lattice parameter but it increased the incubation time of the first hydrogenation. However, the replacement of vanadium by ferrovanadium did not have a significant impact on the hydrogen capacities, heat of formation, and entropy. The main drawback of these FeV substituted alloys is an important loss of capacity after only one cycle. This behaviour should be studied more thoroughly.

Author Contributions: Conceptualization, J.-L.B. and J.H.; Formal Analysis, T.B.; Investigation, T.B and C.G.; Supervision J.-L.B. and J.H.

Funding: This research was funded in part by NSERC grant.

Conflicts of Interest: The authors declare no conflict of interest.

\section{References}

1. Reilly, J.J.; Wiswall, R.H.; Hoffman, K.C.; Waide, C.H. Metal Hydrides as Hydrogen Storage Media; Brookhaven National Laboratory: Suffolk County, NY, USA, 1974.

2. Akiba, E.; Okada, M. Metallic Hydrides III: Body-Centered-Cubic Solid-Solution Alloys. MRS Bull. 2002, 27, 699-703. [CrossRef] 
3. Nakamura, Y.; Akiba, E. New hydride phase with a deformed FCC structure in the Ti-V-Mn solid solution-hydrogen system. J. Alloys Compd. 2000, 311, 317-321. [CrossRef]

4. Nomura, K.; Akiba, E. $\mathrm{H}_{2}$ absorbing-desorbing characterization of the Ti-V-Fe alloy system. J. Alloys Compd. 1995, 231, 513-517. [CrossRef]

5. Ulmer, U.; Asano, K.; Patyk, A.; Enoki, H.; Nakamura, Y.; Pohl, A.; Dittmeyer, R.; Fichtner, M. Cost reduction possibilities of vanadium-based solid solutions-Microstructural, thermodynamic, cyclic and environmental effects of ferrovanadium substitution. J. Alloys Compd. 2015, 648, 1024-1030. [CrossRef]

6. Dou, T.; Wu, Z.; Mao, J.F.; Xu, N.X. Application of commercial ferrovanadium to reduce cost of Ti-V-based BCC phase hydrogen storage alloys (vol 476, pg 34, 2008). Mater. Sci. Eng. Struct. Mater. Prop. Microstruct. Process. 2009, 509, 115. [CrossRef]

7. Mi, J.; LÜ, F.; Liu, X.; Jiang, L.; Li, Z.; Wang, S. Enhancement of cerium and hydrogen storage property of a low-cost Ti-V based BCC alloy prepared by commercial ferrovanadium. J. Rare Earths 2010, 28, 781-784. [CrossRef]

8. Mi, J.; Guo, X.; Liu, X.; Jiang, L.; Li, Z.; Hao, L.; Wang, S. Effect of Al on microstructures and hydrogen storage properties of $\mathrm{Ti}_{26.5} \mathrm{Cr}_{20}\left(\mathrm{~V}_{0.45} \mathrm{Fe}_{0.085}\right)_{100-\mathrm{x}} \mathrm{Al}_{\mathrm{x}} \mathrm{Ce}_{0.5}$ alloy. J. Alloys Compd. 2009, 485, 324-327. [CrossRef]

9. Huang, T.; Wu, Z.; Xia, B.; Chen, J.; Yu, X.; Xu, N.; Lu, C.; Yu, H. TiCr ${ }_{1.2}(\mathrm{~V}-\mathrm{Fe})_{0.6}$-A novel hydrogen storage alloy with high capacity. Sci. Technol. Adv. Mater. 2003, 4, 491-494. [CrossRef]

10. Yan, Y.; Chen, Y.; Wu, C.; Tao, M.; Liang, H. A low-cost BCC alloy prepared from a FeV80 alloy with a high hydrogen storage capacity. J. Power Sources 2007, 164, 799-802. [CrossRef]

11. Mao, Y.; Yang, S.; Wu, C.; Luo, L.; Chen, Y. Preparation of $(\mathrm{FeV} 80)_{48} \mathrm{Ti}_{26+\mathrm{x}} \mathrm{Cr}_{26}(\mathrm{x}=0-4)$ alloys by the hydride sintering method and their hydrogen storage performance. J. Alloys Compd. 2017, 705, 533-538. [CrossRef]

12. Aoki, M.; Noritake, T.; Ito, A.; Ishikiriyama, M.; Towata, S.-I. Improvement of cyclic durability of Ti-Cr-V alloy by Fe substitution. Int. J. Hydrog. Energy 2011, 36, 12329-12332. [CrossRef]

13. Taizhong, H.; Zhu, W.; Jinzhou, C.; Xuebin, Y.; Baojia, X.; Naixin, X. Dependence of hydrogen storage capacity of $\mathrm{TiCr}_{1.8-\mathrm{X}}(\mathrm{VFe})_{\mathrm{X}}$ on V-Fe content. Mater. Sci. Eng. A 2004, 385, 17-21. [CrossRef]

14. Taizhong, H.; Zhu, W.; Baojia, X.; Naixin, X. Effect of stoichiometry on hydrogen storage performance of Ti-Cr-VFe alloys. Intermetallics 2005, 13, 1075-1078. [CrossRef]

15. Kim, J.-H.; Han, K.-S.; Hwang, K.-T.; Kim, B.-G.; Kang, Y.-M. Effect of heat treatment on microstructure and hydrogen storage properties of mass-produced $\mathrm{Ti}_{0.85} \mathrm{Zr}_{0.13}(\mathrm{Fex}-\mathrm{V})_{0.56} \mathrm{Mn}_{1.47} \mathrm{Ni}_{0.05}$ alloy. Int. J. Hydrog. Energy 2013, 38, 6215-6220. [CrossRef]

16. Santos, S.F.; Huot, J. Hydrogen storage in Ti-Mn-(FeV) BCC alloys. J. Alloys Compd. 2009, 480, 5-8. [CrossRef]

17. Santos, S.F.; Huot, J. Hydrogen storage in $\mathrm{TiCr}_{1.2}(\mathrm{FeV})_{\mathrm{X}} \mathrm{BCC}$ solid solutions. J. Alloys Compd. 2009, 472, 247-251. [CrossRef]

18. Tousignant, M.; Huot, J. Replacement of vanadium by ferrovanadium in Ti-based BCC alloys for hydrogen storage. Solid State Phenom. 2011, 170, 144-149. [CrossRef]

19. Sakaki, K.; Kim, H.; Enoki, H.; Yoshimura, S.I.; Ino, S.; Nakamura, Y. Development of TiZrMn based hydrogen storage alloys for a soft actuator. Mater. Trans. 2014, 55, 1168-1174. [CrossRef]

20. Bibienne, T.; Razafindramanana, V.; Bobet, J.-L.; Huot, J. Synthesis, characterization and hydrogen sorption properties of a Body Centered Cubic 42Ti-21V-37Cr alloy doped with $\mathrm{Zr}_{7} \mathrm{Ni}_{10}$. J. Alloys Compd. 2015, 620, 101-108. [CrossRef]

21. Bibienne, T.; Bobet, J.-L.; Huot, J. Crystal structure and hydrogen storage properties of body centered cubic 52Ti-12V-36Cr alloy doped with $\mathrm{Zr}_{7} \mathrm{Ni}_{10}$. J. Alloys Compd. 2014, 607, 251-257. [CrossRef]

22. BRUKER_AXS. TOPAS V5: General Profile and Structure Analysis Software for Powder Diffraction Data; Bruker: Karlsruhe, Germany, 2014.

23. Shannon, R.D. Revised effective ionic radii and systematic studies of interatomic distances in halides and chalcogenides. Acta Crystallogr. Sect. A 1976, 32, 751-767. [CrossRef]

24. Akiba, E.; Iba, H. Hydrogen Absorption by Laves Phase Related BCC Solid Solution. Intermetallics 1998, 6, 461-470. [CrossRef]

25. Okada, M.; Kuriiwa, T.; Tamura, T.; Takamura, H.; Kamegawa, A. Ti-V-Cr b.c.c. alloys with high protium content. J. Alloys Compd. 2002, 330-332, 511-516. [CrossRef]

26. Miraglia, S.; De Rango, P.; Rivoirard, S.; Fruchart, D.; Charbonnier, J.; Skryabina, N. Hydrogen sorption properties of compounds based on BCC $\mathrm{Ti}_{1-\mathrm{x}} \mathrm{V}_{1-\mathrm{y}} \mathrm{Cr}_{1+\mathrm{x}+\mathrm{y}}$ alloys. J. Alloys Compd. 2012, 536, 1-6. [CrossRef] 
27. Cho, S.-W.; Enoki, H.; Kabutomori, T.; Park, C.-N.; Akiba, E. Isotope effect on structural transitions of $\mathrm{Ti}_{1.0} \mathrm{Cr}_{1.5} \mathrm{~V}_{1.7} \mathrm{H}_{\mathrm{x}}\left(\mathrm{D}_{\mathrm{x}}\right)$ with hydrogenation. J. Alloys Compd. 2001, 319, 196-203. [CrossRef]

28. Bibienne, T.; Bobet, J.-L.; Huot, J. Université du Québec à Trois-Rivières, Trois-Rivières. Entropy-enthalpy compensation in Ti-V-Cr BCC alloys used as hydrogen storage materials. Unpublished work. 2018. 